\title{
Entre 117 e 1344: qual o limite diário recomendável para a visitação da caverna Santana (PETAR-SP)?
}

\section{Between 117 and 1344: what is the tourist carrying capacity of Santana cave (PETAR, SP, Brazil)?}

\author{
Heros Augusto Santos Lobo
}

\section{RESUMO}

A capacidade de carga turística (CCT) é um conceito amplamente utilizado na gestão do turismo em áreas naturais. Em cavernas turísticas brasileiras, a CCT vem sendo utilizada quase que unicamente para limitar a quantidade diárias de visitas em uma caverna. Na caverna Santana, diferentes limites diários de visitação foram obtidos em estudos desta natureza, trazendo incerteza para a gestão do atrativo. O objetivo deste artigo é apresentar uma análise dos estudos de CCT realizados na caverna Santana, com base em revisão bibliográfica e documental e focando nos métodos utilizados, bem como suas lacunas e os resultados obtidos. Os resultados evidenciaram uma variação significativa nos estudos de CCT da caverna Santana, com limites diários de 117, 132, 135, 242, 270, 327, 378 e 1344 visitas por dia. Três destes resultados foram obtidos com o uso de métodos desenvolvidos especificamente para a caverna Santana (327, 378 e 1344 visitas/dia). Por outro lado, nenhum destes resultados foi validado com o uso de monitoramentos de longo prazo do ambiente cavernícola em relação aos impactos da visitação. Considerando os aspectos analisados pesquisa, as conclusões recomendam que o limite atual de 117 visitas/dia seja alterado por outro mais bem ajustado à realidade ambiental e social desta caverna turística. O limite atual deve ser substituído pelo resultado obtido no estudo mais preciso sobre CCT realizado na caverna - 378 visitas/dia -, bem como devem ser estabelecidos protocolos de monitoramento das principais variáveis recomendadas no método de capacidade de carga do Plano de Manejo Espeleológico da caverna: temperatura do ar, dióxido de carbono e a distribuição da fauna subterrânea. Estas modificações sugeridas poderão ajudar aos pesquisadores e gestores na obtenção de uma resposta mais acurada sobre os limites de visitação da caverna Santana.

PALAVRAS-CHAVE: Ecoturismo; Espeleoturismo; Capacidade de Carga Turística; Cavernas Turísticas; Áreas Protegidas. 


\section{ABSTRACT}

Tourist carrying capacity (TCC) is a concept widely applied to management of tourism in natural areas. In Brazilian show caves, TCC is used just to limit the daily number of visitors. In Santana cave, different limits of visitors were obtained in several studies, giving uncertainty to the cave managers. The purpose of this article is to show an analysis of all studies about TCC in Santana cave, based in secondary data and focusing in the used methods and related gaps and results of each research. The results show a range of variation of $117,132,135,242,270,327,378$ and 1344 visitors per day in Santana cave. Three of these numbers were obtained using methods that were developed specifically to Santana cave (327, 378 and 1344 visitors/day). Otherwise, any of these limits were still analyzed using longterm monitoring of environment in relation to the impact of visitors. Considering this, it was recommended to change the present daily limit of 117 visitors/day for another one which gives a better adjustment with the environmental and social aspects of this show cave. The current limit should be replaced for the result obtained in the most accurate study made in the cave - 378 visitors/day - and establish monitoring protocols of the main variables recommended in the carrying capacity method of the Plan of Speleological Management of the cave: air temperature, carbon dioxide and subterranean fauna distribution. These modifications could help the researchers and managers to improve the answer to the question about the limit of visitation of Santana cave.

KEYWORDS: Ecotourism; Tourism in Caves; Tourist Carrying Capacity; Show Caves; Natural Protected Areas.

\section{Introdução}

A capacidade de carga turística (CCT) é um procedimento de planejamento e gestão que vêm sendo utilizado há décadas em diversas partes do mundo por alguns pesquisadores (e.g. CIFUENTES, 1992; ZELENKA; KACETL, 2014) e criticado por outros (e.g WAGAR, 1974; DELGADO, 2007). Segundo Cifuentes (1992), o conceito da capacidade de carga teve origem no manejo de pastagens na atividade pecuária. A finalidade original era identificar a área ideal para a criação de cabeças de gado, em função de aspectos pedológicos (granulometria, compactação), bióticos (tipo de pastagem, consumo per capita) e de sociabilidade (espaço disponível, segurança).

Em meados dos anos de 1960, esta abordagem começou a ser utilizada no turismo em áreas naturais, com o intuito de estabelecer limites de uso para as atividades humanas. A essência da CCT se baseava na premissa de que a análise de fatores do ambiente traria as respostas necessárias para a obtenção de um número ideal de visitantes por um período de tempo (WAGAR, 1964, 1974; MANNING, 2002; McCOOL; LIME, 2001), o que passou a ser denominado de "número mágico" por alguns autores (e.g. McCOOL; LIME, 2001). 
As aplicações mais usuais da CCT são em trilhas recreativas (e.g. CIFUENTES-ARIAS et al., 1999) e áreas de mergulho em arrecifes (e.g. ZAKAIA; CHADWICK-FURMAN, 2002). No caso das cavernas - objeto deste estudo -, os pesquisadores europeus foram os que mais desenvolveram trabalhos específicos sobre o tema. Estudos fundamentais foram publicados por Cigna (1993), Hoyos et al. (1998) e Mangin et al. (1999). Estes autores contribuíram para a consolidação de uma base conceitual inicial sobre a CCT, em conjunto com o australiano Gillieson (1996). Metodologias aplicadas foram desenvolvidas nos trabalhos de Hoyos et al. (1998), Calaforra et al. (2003) e Fernández-Cortés et al. (2006). Estes autores se basearam nas relações lineares de causa e efeito entre parâmetros espeleoclimáticos e a presença de visitantes. Em seus estudos, buscaram limitar a visitação em larga escala em situações específicas, como as cavernas que abrigam pinturas rupestres e minerais raros em seu interior.

Em meio a este cenário, a aplicação de metodologias de capacidade de carga turística em cavernas (CCC) iniciou-se no Brasil na última década do século XX. Os trabalhos pioneiros foram realizados nas grutas do Lago Azul e Nossa Senhora Aparecida, em Bonito (MS). Nestes estudos, o método de CCT desenvolvido para trilhas recreativas por Cifuentes (1992) foi adaptado para o uso em cavernas. A iniciativa recebeu também influência dos trabalhos europeus de CCC, o que se nota pela tentativa de uso de variáveis espeleoclimáticas nos estudos realizados (BOGGIANI et al., 2001, 2007).

No Estado de São Paulo, a CCC começou a ser usada aproximadamente no mesmo período, em cavernas turísticas localizadas no interior de Unidades de Conservação estaduais. De todas as cavernas utilizadas para os estudos, nenhuma recebeu tantos esforços como a caverna Santana. Sua popularidade em meio aos roteiros ecoturísticos do Estado e aos estudos de espeleologia e carste (e.g. KARMANN, 1994; CRUZ Jr. et al., 2005), aliada à sua inerente fragilidade, levaram a diversas preocupações sobre seu manejo e conservação (e.g. LINO, 1976; FIGUEIREDO, 2000; MARINHO, 2002; SCALEANTE, 2003; NEIMAN, 2007). Dentre as preocupações, foi se evidenciando a questão dos limites de visitação, a qual foi materializada, também, por meio de diversos estudos de CCC.

Neste contexto, apresenta-se neste artigo uma revisão documental sobre as diversas tentativas de compreensão da capacidade de carga turística da caverna Santana. Para a realização da revisão, além do material já existente no banco de dados do autor, pesquisas com o uso combinado de termos como "capacidade de carga", "capacidade de suporte", "PETAR" e "caverna Santana" foram realizadas em bancos de teses e dissertações (USP, Unesp, Unicamp, UFSCar e UFPR), periódicos científicos e buscadores de sites na internet. Também foram consultados os Planos de Manejo Espeleológico das cavernas do PETAR e seus anexos.

O objetivo central da revisão é discutir as diferenças dos métodos utilizados para a obtenção da CCC. Especificamente, buscou-se contrastar os métodos desenvolvidos para outros tipos de atrativos e que foram 
adaptados para uso em cavernas com os métodos desenvolvidos para cavernas. Além disso, objetivou-se identificar e analisar as recomendações de manejo e gestão do turismo na caverna Santana em cada estudo realizado. Em cada publicação sobre a CCC da caverna Santana identificada, foram analisados: a) o contexto em que o trabalho foi produzido; b) o método utilizado em função dos recursos disponíveis e do desenvolvimento das técnicas de gestão; c) os resultados obtidos, comparando os limites numéricos entre si e com a realidade de visitação; e d) as características e aplicabilidade das demais recomendações de gestão para a caverna Santana, para além dos eventuais limites numéricos sugeridos.

\section{Caracterização turística da área de pesquisa}

O registro de uma caverna associada à ressurgência do rio Roncador é datado de 1907. Os trabalhos de campo realizados por Richard Krone no vale do Ribeira se constituem na menção mais antiga conhecida sobre a caverna Santana, embora o explorador não tenha nela adentrado, mas sim, registrado sua existência e localização (BRANDI, 2008; FIGUEIREDO, 2010). A caverna corresponde à ressurgência de um importante sistema cárstico (Pérolas-Santana), o qual está parcialmente protegido pelo Parque Estadual Turístico do Alto Ribeira (PETAR), no município de Iporanga, à 330 $\mathrm{km}$ da capital do Estado, São Paulo. O roteiro de visitação atual (Figura 1) se estende por aproximadamente $487 \mathrm{~m}$ (LOBO, 2005), de um total de $8.540 \mathrm{~m}$ de extensão já mapeados (SBE, 2017).
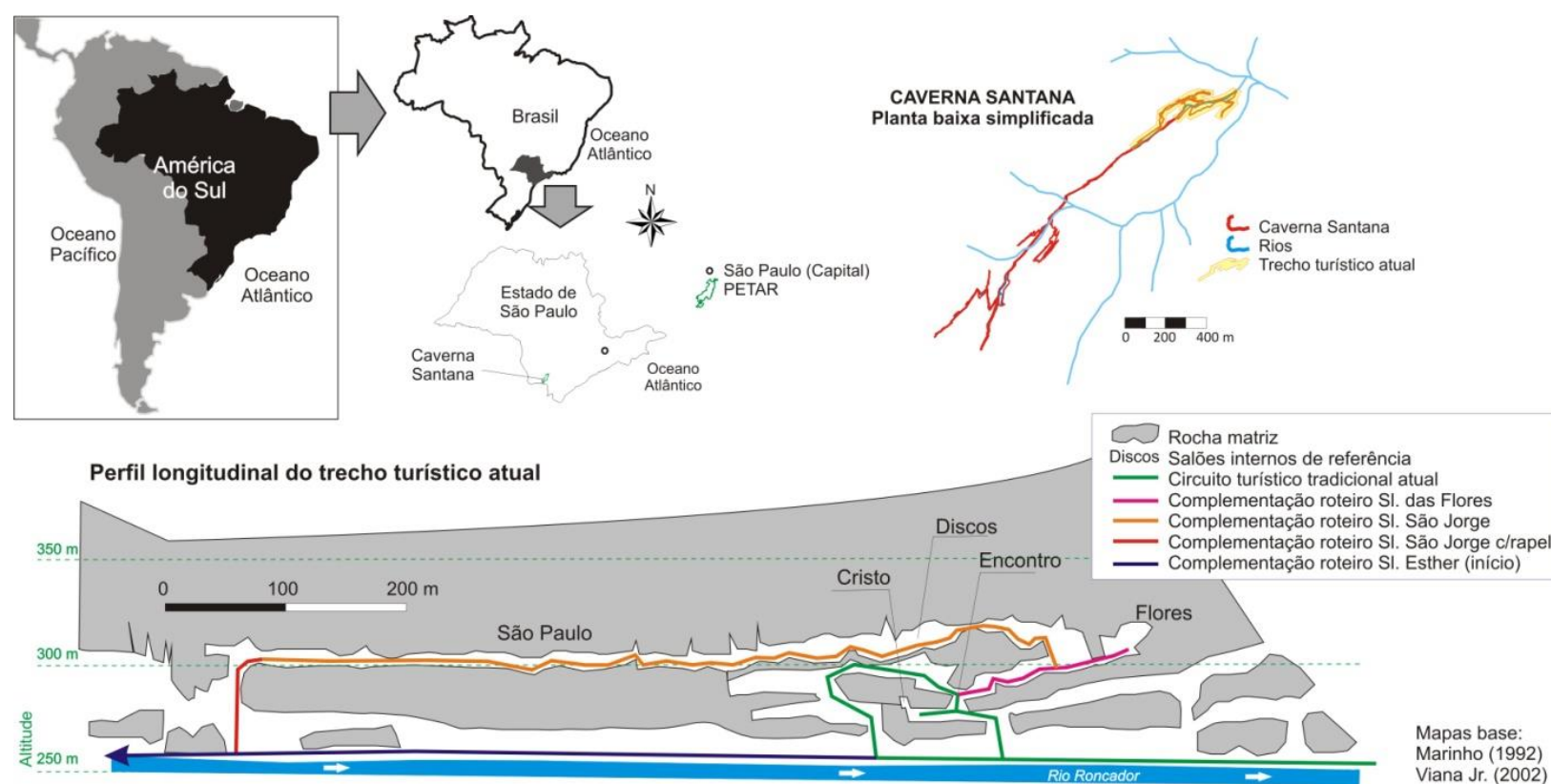

Figura 1: Localização da caverna Santana, incluindo esboço em perfil do roteiro turístico atual e roteiros propostos em seu Plano de Manejo Espeleológico.

Figure 1: Location of Santana cave and a profile of the present tourist route and proposed tours of its plan of speleological management. 
A caverna Santana não possui iluminação fixa em seu interior, a visitação é feita com apoio de lanternas carregadas pelos monitores ambientais e visitantes. A infraestrutura de visitação é rudimentar, com algumas passarelas sobre os trechos de rio, bem como escadas entre os níveis de galerias. Os materiais utilizados para as infraestruturas são a madeira, os arranjos de blocos de rocha e o concreto. Seus principais atrativos são seus salões ornamentados, em função da variedade e quantidade de espeleotemas.

A infraestrutura incipiente, os atrativos existentes, a facilidade relativa de acesso e a Mata Atlântica onde está encravada, levaram à compreensão do roteiro de visitação da Santana como sendo um produto de ecoturismo. A menção sempre se deu em uma concepção mercadológica do termo, sem uma análise mais profunda de enquadramento em algum conceito predominante de ecoturismo. No entanto, nota-se evidente viés no Turismo de Base Comunitária (sensu BARTHOLO Jr. et al., 2011) e mesmo no Ecoturismo na concepção ambientalista de Fennell (2014). Em tempos mais recentes, também vem sendo denominado de espeleoturismo (BORSANELLI; LOBO, 2015).

De um modo geral, o perfil atual de visitantes da Santana é categorizado em seu Plano de Manejo Espeleológico (PME) em dois grandes grupos: os turistas de lazer, que predominam aos finais de semana, feriados e férias; e os grupos escolares, cujas visitas são desenvolvidas para fins de educação ambiental, estudo do meio e aulas de campo (FUNDAÇÃO FLORESTAL, 2010).

\section{Limites de visitação em áreas naturais: uma questão ou uma premissa?}

O preceito de criar limites de uso não é exclusivo para o turismo em áreas naturais. No entanto, foi em ambientes "preservados", notadamente em áreas naturais protegidas, que o tema ganhou força de mandamento nas últimas décadas. Neste contexto, popularizou-se no Brasil uma ideia predominante de uso público das áreas naturais protegidas, na qual a questão do limite de visitação se consolida por uma premissa fundamental: a baixa escala de visitação, como pode ser observado em Ministério do Turismo (2010), entre outros. Trata-se da adoção de uma premissa prematura para um problema que é essencialmente mais amplo e não se resolve apenas em função de aspectos quantitativos. É preciso considerar que nem toda visitação em larga escala se caracteriza essencialmente como "turismo de massa" (sensu ZAOUAL, 2008). O padrão predatório e irresponsável de visitação pode ser observado mesmo em grupos de poucas pessoas ou a partir da índole de um único indivíduo, com interesses de visitação que vão para além da fruição responsável e harmoniosa do ambiente visitado.

No entanto, desde o momento em que a premissa da baixa escala de visitação passou a ser considerada como um princípio básico do uso público em áreas naturais protegidas, a CCT passou a ser utilizada com uma finalidade dominante: limitar a quantidade de visitantes em um determinado 
atrativo. Trata-se de uma distorção intencional de um conjunto de princípios que foi desenvolvido com o objetivo de identificar até que ponto o uso turístico é possível sem causar danos no ambiente, como definem Cifuentes (1992) e Mexa e Coccossis (2004). Mas, no contexto atual, a CCT vem sendo utilizada com o objetivo de produzir uma limitação de uso condicionada à obtenção de números baixos como resultado. Esta forma de conduzir a CCT não somente distorce suas possibilidades, mas cria uma relação fundamentalista entre a teoria e a prática de gestão do uso público das áreas naturais protegidas.

Do ponto de vista dos procedimentos de obtenção da CCT, desde os anos de 1990 o cenário nacional foi quase que dominado por um único modelo teórico, conceitual e prático: o método de Cifuentes. A origem deste método ocorreu no contexto de áreas protegidas da Costa Rica (Cifuentes, 1992) e com aplicação posterior do mesmo autor e colaboradores em outras trilhas turísticas costarriquenhas (Cifuentes-Arias et al., 1999). O método de Cifuentes ganhou força no Brasil, por diversos motivos, dos quais se destacam: a) os limites de recursos dos órgãos gestores - anunciados por eles próprios em muitos casos, tal como feito também no próprio material de Cifuentes-Arias et al. (1999); e b) as premissas dogmáticas que de as áreas protegidas são redutos exclusivos e separados - perspectiva já criticada por trabalhos como o de Diegues (1992).

O método de CCT de Cifuentes determina que o resultado final seja expresso por meio de um número consideravelmente limitado de visitas diárias em um sítio turístico. Isto ocorre porque sua construção processual, dividida em diferentes etapas, reduz cumulativamente o total de visitantes pela somatória de situações-problema (Lobo et al., 2010). Com isso, tornase impossível conhecer os gargalos reais da visitação e, por consequência, estabelecer um monitoramento confiável de uma única variável analisada. Os limites estabelecidos ao final do processo estão sempre muito aquém das possibilidades de resiliência do ambiente. Deste modo, as possibilidades de monitoramento dos impactos da visitação são inutilizadas, ou realizadas para cumprir formalidades técnico-administrativas.

Estes mesmos preceitos de limitação do uso público recreativo como premissa foram transpostos para o planejamento e gestão do turismo em cavernas no Brasil. Notadamente, as iniciativas pioneiras de CCC utilizaram também o método de Cifuentes, como se observa nos trabalhos para as cavernas do Monumento Natural Estadual Gruta do Lago Azul, em Bonito (MS) (BOGGIANI et al., 2001, 2007). Tais trabalhos são reconhecidos pelo pioneirismo de aplicação, guiado pelos limites disponíveis na época de sua execução. Posteriormente, foram tecnicamente transpostos para a realidade da caverna Santana, no PETAR, citando-se como exemplo o também pioneiro trabalho de Sgarbi (2003a). 


\section{Caverna Santana: de uma facilidade para a mineração para as dificuldades do uso público sustentável}

A primeira proposta de uso antrópico para a caverna Santana não se referia ao turismo, mas sim, à mineração. Entre os anos de 1930 e 1932, a caverna esteve entre os alvos da exploração minerária na região, sob coordenação do engenheiro Theodoro Knecht. Para tanto, uma extensa passarela foi construída em seu interior, para facilitar a prospecção mineral. No entanto, uma mudança natural de direção das galerias da caverna fez com que o interesse em a usar para facilitar o acesso para a mineração fosse abandonado (KNECHT, 1935; LE BRET, 1995).

As iniciativas de mineração por meio da caverna Santana foram definitivamente frustradas em 1958, com a criação do Parque Estadual do Alto Ribeira (PEAR), depois alterado em 1960 para Parque Estadual Turístico do Alto Ribeira, o PETAR (LE BRET, 1995; FIGUEIREDO, 2010). A vocação turística da Mata Atlântica e das cavernas da região havia sido mencionada na época da criação do Parque, e com o tempo foi reforçada pela Prefeitura Municipal de Iporanga por meio da caverna Santana. Seu objetivo era fazer frente aos esforços do município vizinho de Eldorado em desenvolver o turismo na caverna do Diabo. No entanto, durante os anos de 1960 e início dos anos de 1970, a visitação da caverna se limitava a poucos curiosos e espeleólogos (LE BRET, 1995). Ainda nos anos de 1970, emergiu uma preocupação mais sólida com a conservação da natureza e cultura na região aliada ao turismo, evidenciada no trabalho de Lino (1976).

Nos anos de 1980 se efetivaram os esforços para a consolidação do uso público no PETAR, com a implantação do Núcleo Santana. Neste período, o Parque começou a se firmar como um destino turístico para aventureiros (Figura 2a), oriundos principalmente de cidades dos estados de São Paulo e Paraná. A existência de áreas de camping no interior do Núcleo Santana (Figura 2b) levou a decisão de se implantar um portão na entrada da caverna homônima (Figura 2c), para coibir a visitação dos campistas fora do horário formal de visitação (MARINHO, 2002).

Os anos de 1990 foram palco de um crescimento vertiginoso da visitação turística no Núcleo Santana, (GIATTI; ROCHA, 2001; MARRA, 2001). Este aumento suscitou a necessidade de novos serviços turísticos na região. Uma das formas de ampliar as oportunidades de emprego e renda se deu por meio da criação dos cursos de Monitores Ambientais, profissionais que ainda fazem o trabalho de condução de visitantes na região e apoiam a conservação dos recursos naturais. O primeiro curso de formação destes profissionais foi ministrado em 1995 e outras iniciativas foram repetidas em 1998 e dos anos 2000 em diante (FIGUEIREDO, 1998; FOGAÇA, 2008).

Além do crescimento numérico de visitantes, a caverna Santana sofreu também o aumento dos impactos ambientais decorrentes da visitação realizada sem a correta ordenação. Se a ameaça da supressão da caverna pela mineração já estava há anos superada, o dano silencioso da exploração desordenada começava a se evidenciar. A formalização desta preocupação foi manifestada por estudos como os de Piva (2003) e Scaleante (2003), que levantaram a hipótese do impacto negativo do uso das carbureteiras como 
fonte de iluminação para a visitação turística. Piva (2003) mencionou que, em determinados períodos, haviam até 40 carbureteiras ligadas simultaneamente dentro da caverna. Em atenção ao intenso impacto - tendo como focos, na época, a temperatura do ar, a concentração de $\mathrm{CO}_{2}$ e a fuligem da queima do acetileno -, Scaleante (2003) pesquisou os impactos higrotérmicos da chama da carbureteira e não constatou maiores problemas do ponto de vista atmosférico. Todavia, consolidou o pressuposto de que a fuligem gerada pela queima do acetileno para acender 0 fogo das carbureteiras gerava poluição visual nos espeleotemas (Figura 2d).

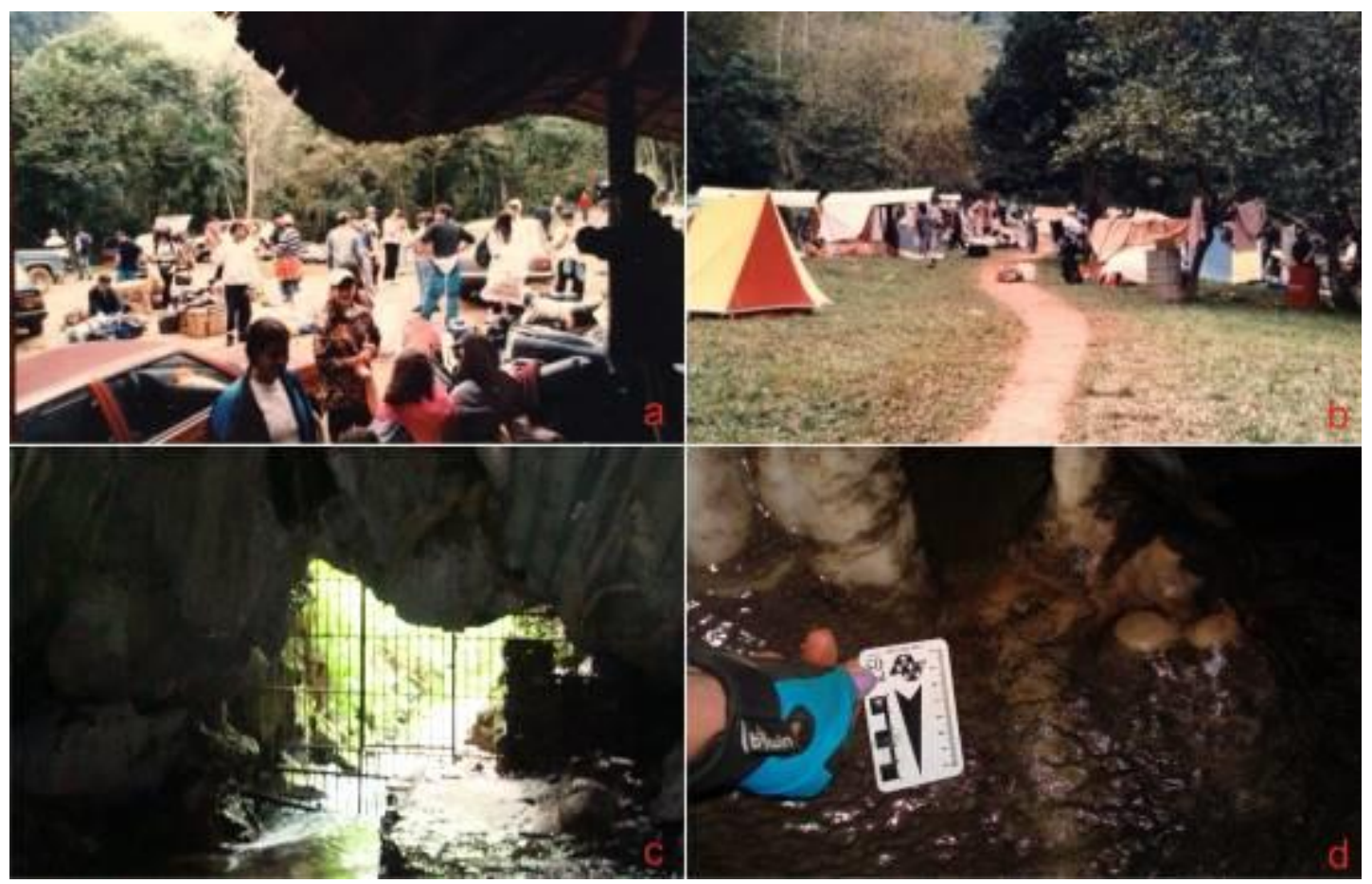

Figura 2. Diferentes situações relacionadas aos impactos ocorridos na caverna Santana no passado: a) Aglomeração de visitantes e automóveis a menos de 150m da entrada da caverna, sem ordenação aparente; b) Área de camping nas proximidades da caverna, às margens do rio Betari; c) Portão instalado na entrada da caverna, para coibir o acesso de campistas fora do horário de visitação; d) Escurecimento dos espeleotemas, causado pela deposição de fuligem gerada pela queima de acetileno nas carbureteiras.

Fotos: a e b: Patrícia R.R. Cacciatori; c e d: o autor.

Fig. 2. Several ocasions related to tourist impacts which ocurred in Santana cave in the past:

a) Crowd of visitors and cars, less then $150 \mathrm{~m}$ of cave entrance, with no apparent organization; b) Camping site close both to Santana cave and Betari river; c) Gate installed at the entrance of the cave to restrain access of campers outside visiting hours; d) Dark lint in cave speleothems caused by carbide lamps.

Photos: a e b: Patrícia R.R. Cacciatori; c e d: the autor.

Os impactos da fuligem produzida pelas carbureteiras (Figura 2d) foram comprovados por estudos posteriores, publicados em Lobo et al. (2015). No entanto, o uso de carbureto para fins de visitação já havia sido proibido desde 2003, para evitar o possível impacto. Outra medida de gestão que contribuiu indiretamente para a redução da pressão sobre a caverna Santana foi o fechamento do camping no Núcleo Santana, em março de 2005. Segundo descreve Piva (2003), havia na época uma mobilização entre 
monitores ambientais e membros da comunidade do Bairro da Serra de Iporanga - a principal comunidade receptora de turistas que vão ao PETAR - para seu fechamento.

De acordo com estes, o camping tornou-se um local com grande índice de promiscuidade (principalmente banhos nus), alto uso de drogas e álcool, roubos, barulho excessivo e desarmônico proveniente de aparelhos de som, além de facilitar o acesso às cavernas durante a noite, aumentando o risco de acidentes e a possibilidade de depredação (PIVA, 2003, p.29).

Com o fechamento, a visitação às cavernas passou a se restringir ao horário de funcionamento do PETAR. O portão instalado na caverna Santana (Figura 2c) também deixou de apresentar funcionalidade - mas somente foi retirado em definitivo em 2008. A retirada do portão foi uma das consequências de um Plano Emergencial de uso da caverna, após fechamento temporário determinado por embargo judicial e posterior reabertura para a visitação (BORSANELLI; LOBO, 2015).

Em síntese, no início dos anos 2000, a visitação da caverna Santana era caracterizada da seguinte forma:

1. Transição do uso de carbureteiras para lanternas elétricas;

2. Limites de visitação ainda pouco precisos, em sua maioria, ordenados pelas possibilidades de condução dos monitores ambientas e pela demanda tanto das agências e organizadores independentes de viagens - que enviavam turistas para a região - quanto das pousadas locais;

3. Aumento da preocupação com os impactos da visitação, sobretudo pelos grandes volumes de visitantes acumulados em finais de semana e feriados. Giatti; Rocha (2001) mencionam dados que demonstram o aumento no número de visitantes no Núcleo Santana: de menos de 10.000 em 1988 para quase 40.000 no ano 2000 . Mencionam também dados para um único dia, durante o final de semana do feriado nacional de Carnaval de 2001: 497 visitantes no sábado e 888 no domingo. Scaleante (2003) apresenta também um registro de 310 visitantes no interior da caverna, em junho de 2002. Vale ressaltar que, nesta época, não havia controle de visitantes nas cavernas. As menções aos limites de visitação feitas na Portaria IF-1, de 19 de maio de 1992 não eram devidamente observadas, gerando uso descontrolado na maioria dos roteiros de visitação, sobretudo os de mais fácil acesso, como a Santana;

4. Cenário de pouca tranquilidade no interior da caverna em períodos de alta temporada, com acúmulo de grupos de visitantes em determinados gargalos da visitação e demora demasiada nos pontos de interpretação. 
Dentre as consequências deste cenário, ressalta-se aquela que se relaciona com o tema deste estudo: o desconhecimento da capacidade de resiliência e do limite de suporte do ambiente subterrâneo da Santana à presença humana. Faltavam estudos de causa e efeito entre os impactos gerados pela visitação e a capacidade do ambiente em absorvê-los ou dispersá-los. Este cenário esteve entre os fatores que motivaram os diversos estudos de gestão da visitação e capacidade de carga turística na caverna Santana.

\section{Estudos de capacidade de carga turística na caverna Santana}

No final dos anos de 1990 e início dos anos 2000, estudos como os de Allegrini (1999), Piva (2003) e Sgarbi (2003a) estavam entre os que demonstravam a necessidade de se elaborar um plano de manejo para o Parque e outro específico para as cavernas, em função do ambiente sensível e da necessidade de ordenar a visitação. A capacidade de carga das cavernas estava entre as necessidades levantadas nestes e em outros estudos. De forma prática, a abordagem deste tema específico era feita, sobretudo, com base nos trabalhos similares desenvolvidos para trilhas turísticas na Costa Rica (CIFUENTES, 1992; CIFUENTES-ARIAS et al., 1999).

Para a caverna Santana, a primeira menção aos limites de visitação ocorreu neste mesmo período. Embora não se tratasse de um estudo específico de capacidade de carga turística, a Portaria IF-1 de 19 de maio de 1992 apresenta dados que permitem obter um número inicial. Com o objetivo anunciado de ordenar a visitação no PETAR em função do aumento significativo do número de visitantes, o documento definiu o que chamou de "procedimentos específicos" para a visitação de algumas cavernas. O documento também faz menção à "capacidade de suporte ecológico", mas em relação apenas ao camping que existia no Núcleo Santana na época, não às cavernas. Para a caverna Santana, os procedimentos específicos de visitação foram os seguintes: grupos de no mínimo 3 e no máximo 8 visitantes, acompanhados de um monitor ambiental, com intervalo de $15 \mathrm{~min}$ entre os grupos e duração média de 1h30min de atividade, entre as 8:00h e 17:00h. Embora não tenha se preocupado em apresentar um número final de capacidade de carga, os dados permitem obtê-lo usando os coeficientes de rotatividade: máximo de 30 grupos por dia (1 a cada 15 minutos, iniciando às 8:00h e com o último entrando na caverna às 15:30h, para sair até o horário de fechamento do Parque), com 9 pessoas no máximo em cada grupo (8 visitantes e um monitor ambiental). Com isso, seria possível a realização de até 270 visitas/dia na Santana.

O primeiro estudo que mencionou literalmente a capacidade de carga para a Santana foi produzido no início dos anos 2000. Como fruto de um trabalho de Iniciação Científica de um curso de Bacharelado em Biologia da Universidade Mogi das Cruzes (UMC), Marcelo Caetano Sgarbi (in memmoriam) utilizou os mesmos equipamentos de monitoramento atmosférico que foram utilizados anteriormente na gruta do Lago Azul, 
cedidos pelo IPHAN-MS com o intermédio do prof. Dr. Paulo Cesar Boggiani. Sgarbi fez estudos-piloto na Santana e também na gruta do Chapéu - esta última, localizada no Núcleo Caboclos do PETAR -, sob a orientação da profa. Dra. Rosely A. L. Imbernon e coorientação do prof. Dr. Ivo Karmann. Seus resultados para a caverna Santana enfatizaram a deterioração existente na galeria superior do circuito de visitação. Para o autor, este trecho possuía nível de circulação de energia (NCE) baixo e, portanto, deveria ser excluído da visitação. Os NCEs se referem a um conceito dos anos de 1970, largamente utilizado no Brasil pelos pesquisadores e técnicos ligados à gestão do turismo em cavernas, à partir do trabalho de Heaton (1986). Foi mencionado, por exemplo, nos trabalhos de Scaleante (2003) na caverna Santana e Boggiani et al. (2007) na gruta do Lago Azul, em Bonito (MS).

No caso da Santana, os trabalhos de Sgarbi $(2003 a, b)$ não apresentaram as variáveis utilizadas para determinar os NCEs dos diversos trechos da caverna. No entanto, o autor sugere a substituição da visitação no trecho arbitrado como NCE baixo por outro mais longo na galeria do rio (Sgarbi, 2003a), onde o NCE foi definido como alto. Para a capacidade de carga turística, Sgarbi utilizou o método de Cifuentes (1992), definindo uma Capacidade de Carga Real (CCR) de 430 visitantes/dia para o circuito proposto, sem a galeria superior (Sgarbi, 2003a,b). No entanto, o autor não explicou em seus trabalhos como este número foi obtido, pois não apresentou os cálculos executados e nem as variáveis utilizadas - com exceção da temperatura do ar.

O método de capacidade de carga turística de Miguel Cifuentes Arias foi também utilizado em outros quatro estudos na caverna Santana. O primeiro deles foi desenvolvido por Heros Augusto Santos Lobo, por meio de uma pesquisa vinculada à Universidade Estadual de Mato Grosso do Sul (UEMS). Os trabalhos de campo tiveram o apoio da espeleóloga Silmara Zago, da União Paulista de Espeleologia (UPE) e do guia local, espeleólogo e ambientalista Sr. Joaquim Justino dos Santos (in memmoriam), popularmente conhecido como "JJ". Os resultados foram publicados no XXVIII Congresso Brasileiro de Espeleologia, no ano de 2005.

Conforme publicado em Lobo (2005), das três etapas do cálculo de Cifuentes-Arias et al. (1999), duas foram executadas: a capacidade de carga física (CCF) e a CCR. Na CCR, foram utilizados três fatores de correção (FCs), sendo dois deles adaptados do método original: o grau de dificuldade e o fator social. $\mathrm{O}$ terceiro $\mathrm{FC}$ foi baseado em uma classificação proposta para os NCEs dos diferentes setores da caverna. Neste estudo, o NCE da galeria superior foi majoritariamente classificado como moderado, diferindo do proposto por Sgarbi (2003a). Apenas os Salões Cavalo e Cristo foram classificados como NCE Baixo. Na galeria do rio Roncador, tanto Sgarbi (2003a) quanto Lobo (2005) classificaram o NCE como sendo alto. Com base nestes parâmetros, a CCR obtida para a caverna Santana foi de 243,49 visitas/dia, sendo arredondada, para efeitos práticos, para 242 visitas/dia (22 grupos de 11 visitantes, incluso o monitor ambiental). 
A continuidade das pesquisas feitas pelo mesmo pesquisador foi publicada em dois trabalhos: Lobo; Zago (2007) e Lobo (2007), ambos publicados no II Encontro Brasileiro de Estudos do Carste. No primeiro deles, os autores apresentaram nova avaliação para os NCEs da caverna Santana. O NCE da galeria do rio foi reclassificado como moderado, enquanto o da galeria superior foi revisto para baixo, com base no acréscimo de novos indicadores ambientais e observações de seu estado vigente em campo. O segundo trabalho reapresentou o cálculo do FC NCE para a caverna Santana: enquanto Lobo (2005) definia uma limitação da ordem de $49,9 \%$ do total de visitas diárias, Lobo (2007) sugeriu que esta limitação deveria ser da ordem de 26,89\%. Embora o estudo não tenha apresentado um novo valor para a capacidade de carga da caverna Santana, este se torna possível atualizando o cálculo de Lobo (2005) e substituindo o FC NCE original pela nova limitação sugerida. Neste cenário, usando a versão mais restritiva de Lobo (2007), a capacidade de carga da caverna Santana passaria para 131,21 visitas/dia. Em valores aproximados, o limite prático seria de 132 visitas/dia, perfazendo um total de 12 grupos de 11 visitantes.

O ano de 2008 traria uma grande reviravolta no cenário da gestão da caverna Santana e, por consequência, em sua capacidade de carga. No início daquele ano, as cavernas do PETAR foram fechadas por um embargo judicial, justificado, entre outros, pela ausência de um Plano de Manejo Espeleológico (PME). A reabertura das cavernas foi condicionada à elaboração de um Plano Emergencial de uso público para cada caverna, como parte de um Termo de Ajustamento de Conduta (TAC) assinado entre as partes envolvidas (BORSANELLI; LOBO, 2015).

O plano emergencial da caverna Santana teve como uma de suas etapas a elaboração de um "cálculo oficial" de sua capacidade de carga turística. Para tanto, realizou-se uma visita técnica na caverna, com a participação de técnicos de órgão da Secretaria Estadual do Meio Ambiente, do Centro Nacional de Estudo, Proteção e Manejo de Cavernas (CECAV), da comunidade local e pesquisadores convidados. Ao final da visita técnica, os presentes se reuniram e ainda pairavam dúvidas se a caverna seria reaberta junto com as demais que haviam sido fechadas no mesmo processo de embargo. Uma das exigências para a reabertura era a existência de um número "cientificamente definido" de capacidade de carga.

A continuidade das atividades relativas à referida vistoria levou a obtenção de um novo cálculo de capacidade de carga, revisando o que já havia sido publicado e atualizando conforme o conhecimento disponível na ocasião. Para tanto, foi novamente utilizado o método de Cifuentes-Arias et al. (1999) em sua adaptação para o meio subterrâneo. Partindo da CCF definida em Lobo (2005) e usando como FCs o aspecto social e os NCEs novamente aprimorados, chegou-se ao total de 117 visitas/dia. A visitação foi definida com intervalos de $30 \mathrm{~min}$. entre os grupos compostos por 8 visitantes e 1 monitor ambiental (FUNDAÇÃO FLORESTAL, 2008).

Posteriormente, ajustes foram realizados no relatório técnico que foi elaborado para subsidiar o Plano Emergencial da caverna Santana, tendo sido publicado em Lobo (2008). Trata-se do último trabalho que utilizou o 
método de Cifuentes-Arias et al. (1999) para a capacidade de carga na Santana. Nesta versão, o resultado do cálculo realizado para a CCR foi de 120,9539 visitas/dia. Na discussão dos resultados, Lobo (2008) menciona, pela primeira vez nos estudos consultados, a necessidade de se compreender os números obtidos como uma referência inicial para o estudo e monitoramento da visitação, não uma resposta definitiva. Ao final, o autor sugere que a capacidade de carga da Santana seja dividida de forma sazonal, para efeito de testes: 117 visitas diárias nos dias úteis (13 grupos de 9 visitantes, incluindo o monitor ambiental) e 135 visitas diárias nos finais de semana e feriados (um acréscimo de 2 grupos por dia).

O uso do método de Cifuentes-Arias et al. (1999) na caverna Santana se encerrou com os trabalhos para a elaboração de seu Plano de Manejo Espeleológico. Neste momento da trajetória, a Fundação Florestal (órgão gestor responsável pelo PETAR) e o Instituto Ekos Brasil (OSCIP contratada para executar os PMEs) contaram com uma equipe de especialistas de diversas áreas do conhecimento, para cumprir os estudos necessários para o manejo da Santana e outras cavernas da região. Dentre os diversos participantes deste projeto, um grupo de pesquisadores e técnicos se debruçou sobre a meta de propor uma nova forma de obtenção da Capacidade de Carga Turística. O grupo era composto pelos pesquisadores Bárbara Nazaré Rocha, Eleonora Trajano, Francisco Vilela Laterza, Heros Augusto Santos Lobo, José Antonio Basso Scaleante, Maria Elina Bichuette, Maurício de Alcântara Marinho e Oscarlina Aparecida Furquim Scaleante. Em comum acordo, foram pensadas diretrizes para nortear um caminho alternativo para a capacidade de carga:

1. Realizar, simultaneamente, os estudos de capacidade de carga de quase 50 roteiros de visitação, em 32 cavernas, no período de um ano;

2. Não utilizar "números mágicos" (citando MANNING, 2002), mas sim, premissas lógicas de uso responsável e conservação ambiental (MEXA; COCCOSSIS, 2004);

3. Considerar as relações de causa e efeito, nas fragilidades do ambiente, relativas ao nível de pressão exercido pelo uso público (TRAJANO, 2010);

4. Permitir o envolvimento dos stakeholders locais na decisão sobre os limites de uso (FUNDAÇÃO FLORESTAL, 2010);

5. Conciliar a necessidade de estabelecer limites de visitação com o zoneamento ambiental espeleológico - este último, exigido nos PMEs como ferramenta de planejamento espacial (CONAMA, 2004; FUNDAÇÃO FLORESTAL, 2010).

Com base nestas diretrizes, foi desenvolvido um método de capacidade de carga provisória, que funciona como suporte à tomada de decisão. O método parte de uma hipótese de visitação, a qual é denominada de "cenário". Cada cenário de visitação deve ser apresentado com suas características qualitativas e quantitativas (LOBO et al., 2013). As características qualitativas se referem ao perfil do público atendido, a forma 
como a visitação será feita e dados gerais do roteiro. As características quantitativas correspondem aos dados da Capacidade de Carga Física do método de Cifuentes (1992): número de pessoas por grupo, número de grupos por dia, tempo total do roteiro e intervalo de tempo entre os grupos.

Utilizando o método da Capacidade Carga Provisória (LOBO et al., 2013), no PME da caverna Santana foram considerados 6 possíveis roteiros para atender distintos perfis de público, cujos limites provisórios de uso são apresentados na Tabela 1. Os roteiros com limites menores de visitação por dia correspondem a áreas mais frágeis da caverna. Nestes roteiros, também se optou por uma proporção maior de monitores ambientais por visitante, por razões de segurança - tanto para o ambiente quanto para o visitante. $O$ sexto roteiro, o qual não consta na Tabela 1, foi proposto para ser implantado pela galeria do rio até o poço São Jorge. Trata-se de uma proposta de ampliação da passarela de visitação hoje existente na caverna, com a possibilidade de levar cadeirantes e outras Pessoas com Deficiência $(\mathrm{PcD})$.

Tabela 1: Roteiros de visitação previstos na caverna Santana e respectivos limites diários de visitação. Adaptado de Fundação Florestal (2010).

Table 1: Tour routes planned in Santana cave and respective daily limits of visitation. Adapted from Fundação Florestal (2010).

radicional (contemplação)

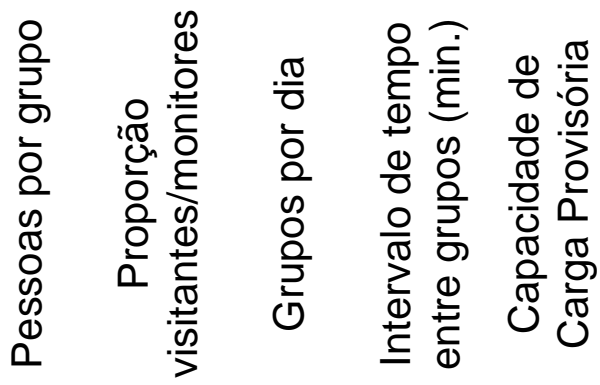

\begin{tabular}{|c|c|c|c|c|c|}
\hline 1. Tradicional (contemplação) & 18 & $8 / 1$ & 16 & 25 & 288 \\
\hline 2. Tradicional (escolas) ${ }^{\star \star}$ & 27 & $8 / 1$ & 11 & 35 & 297 \\
\hline 3. Salão Ester ${ }^{\star \star \star}$ & 6 & $2 / 1$ & 2 & 60 & 12 \\
\hline 4. Salão São Jorge ${ }^{\star \star \star \star}$ & 6 & $2 / 1$ & 2 & 180 & 12 \\
\hline 5. Salão das Flores ${ }^{\star \star \star \star \star ~}$ & 6 & $5 / 1$ & 1 & & 6 \\
\hline
\end{tabular}

* Grupos menores para público geral, visando melhorar o controle da visitação. Tempo médio de percurso de 2 horas/grupo.

** Apenas em dias úteis (Entrada das 8:30 às 15:00h). Proporcionalidade de 01 monitor ambiental/grupo de 8 visitantes, incluindo 1 adulto (guia da agência ou professor) e 7 estudantes. Tempo médio de percurso $=2$ horas/grupo.

${ }^{* * *}$ Horários de entrada na caverna: 8:30h e 9:30h.

**** A presença de dois grupos é permitida para o roteiro circular, com rapel no poço São Jorge e retorno pela galeria do rio. Em caso de retorno pela galeria seca, sem fazer o rapel, deve ser autorizado apenas um grupo por dia. Horários de entrada na caverna: 8:45h e $11: 45 h$.

${ }^{* * * *}$ Horário de entrada na caverna: 9:45h. 
Com base nos dados apresentados na Tabela 1 e considerando todos os roteiros, a capacidade de carga máxima da caverna Santana passou para 327 visitas diárias em dias úteis e 318 visitas diárias em finais de semana e feriados. Estes são os limites previstos no Programa de Uso Público de seu Plano de Manejo Espeleológico. O mesmo documento comenta sobre a necessidade de estudos contínuos e em maior escala de detalhe para que os limites de visitação possam ser revistos continuamente (FUNDAÇÃO FLORESTAL, 2010).

Dando sequência às pesquisas sobre o tema, Heros A. S. Lobo desenvolveu, entre 2007 e 2011, uma pesquisa de doutorado sobre a capacidade de carga turística com base em fatores atmosféricos. A pesquisa foi realizada junto ao Programa de Pós-Graduação em Geociências e Meio Ambiente da Unesp de Rio Claro (SP), sob orientação dos profs. Drs. José Alexandre de Jesus Perinotto e Paulo Cesar Boggiani. A base para a obtenção da capacidade de carga foi um monitoramento da temperatura e umidade relativa do ar, feito por pouco mais de um ano na caverna. A base de dados gerada foi analisada por meio de estatística descritiva e para séries temporais, com o desenvolvimento de algoritmos de cálculo relacionando a quantidade de visitantes por dia com as variações detectadas nas variáveis pesquisadas.

Neste estudo, o cálculo de capacidade de carga turística apresentou um resultado de 1353,7 visitas/dia. Para efeitos práticos, o autor sugeriu a organização da visitação em grupos de até 24 visitantes. Com isso, seriam admissíveis até 56 grupos por dia, em intervalo de $7 \mathrm{~min} 30$ s entre os grupos, totalizando 1344 visitas por dia. Por outro lado, foi também sugerido que os padrões de organização dos grupos de visitantes testados durante a pesquisa fossem adotados na prática, por questões de segurança e organização. Neste caso, os intervalos de entrada entre os grupos seriam de 20 min aos finais de semana e feriados, com 21 grupos diários de 18 visitantes cada, totalizando 378 visitas/dia. Nos dias úteis, seria utilizado o intervalo de entrada entre os grupos de $30 \mathrm{~min}$, permitindo no máximo a entrada de 14 grupos de 24 visitantes cada, perfazendo o total de 336 visitas/dia (LOBO, 2011).

O último estudo publicado sobre a capacidade de carga da caverna Santana também foi de autoria de Heros A. S. Lobo. Trata-se de um artigo publicado em 2015, o qual apresenta os últimos avanços da pesquisa iniciada no doutoramento do autor. Para a versão publicada, foi feita uma alteração em um dos algoritmos de cálculo que relacionam a visitação com os impactos atmosféricos. A modificação permitiu eliminar o caráter demasiadamente hipotético do denominado "intervalo de entrada entre os grupos" de Lobo (2011). Este foi substituído pela análise do "tempo máximo de permanência" em pontos específicos da caverna, considerados como gargalos da visitação (LOBO, 2015).

Outro aspecto destacado deste método foi o teste prático dos cenários de visitação projetados, sob influência do método de Lobo et al. (2013), o qual foi aplicado no PME da caverna (FUNDAÇÃO FLORESTAL, 2010). Foram testados os dois cenários distintos para o roteiro de visitação 
tradicional da caverna citados em Lobo (2011), já descritos anteriormente. Os padrões dos cenários foram baseados em uma versão preliminar do PME da caverna, no qual a visitação prevista para os dias úteis, com escolas, era de no máximo 24 visitantes por grupo. Ambos os cenários foram aprovados nos testes realizados, correspondendo, assim, ao limite diário de visitas na caverna sugerido neste último estudo. $O$ autor menciona também a necessidade de estudos contínuos de monitoramento das variáveis pesquisadas, e o eventual ajuste dos limites propostos, para mais ou para menos, conforme os resultados obtidos (LOBO, 2015).

\section{Discussão}

A definição de limites de uso dos recursos naturais para o turismo esteve entre as principais pautas dos pesquisadores do tema no início dos anos 2000. A ampliação do advento do ecoturismo enquanto forma e postura de visitação (cf. CEBALLOS-LASCURÁIN, 1994; FENNEL, 2000) consolidou uma série de preocupações do período, dentre as quais se destacou o limite de uso dos recursos naturais. Sob a influência do ideário de turismo sustentável (SWARBROOKE, 2000), buscou-se firmar a posição, ainda que velada, de que o consumo turístico dos recursos naturais em áreas frágeis precisava ser reduzido. Muito provavelmente, esta leitura dos conceitos derivou da análise de diversas situações no mundo onde o uso excessivo e desregrado caminhava para a degradação do ambiente (e.g. CIGNA, 1993; HOYOS et al., 1998; CALAFORRA et al., 2003).

A capacidade de carga turística foi inserida neste contexto sob o pretexto de ser um processo científico de obtenção de um limite lógico para o uso dos recursos turísticos. No caso das cavernas, trabalhos publicados no final do Século XX já apontavam para esta necessidade de "limitar numericamente" o uso turístico, como observado em Cigna (1993) e Hoyos et al. (1998). Estes e outros trabalhos geraram um ambiente de preocupação com os limites de uso turístico das cavernas que eram compatíveis com a realidade em que foram produzidos. Na Europa e em outras partes do mundo, com predomínio do Hemisfério Norte, os volumes de visitação em cavernas superavam a grandeza das centenas de milhares de visitantes por ano (CIGNA; BURRI, 2000). Além disso, algumas destas cavernas são abrigos de painéis de pinturas rupestres frágeis. Nestes casos, a alteração sensível dos padrões naturais de flutuação do ambiente pode levar ao comprometimento dos vestígios abrigados (BASTIAN; ALABOUVETTE, 2009), justificando a posição mais restritiva em relação ao uso.

Para o caso do Brasil, as menções à capacidade de carga em cavernas se iniciaram em meados dos anos de 1990. As preocupações emergiram em destinos ecoturísticos, como Bonito (MS) (BOGGIANI et al., 2001) e no próprio PETAR (INSTITUTO FLORESTAL, 1992; ALLEGRINI, 1999; GIATTI; ROCHA, 2001). A caverna Santana era um dos focos de preocupação, por fatores como a sua facilidade de acesso, características físicas atrativas para a visitação - porém frágeis -, o crescimento no volume de visitação e o uso de carbureteiras como fonte de iluminação. Estes dois últimos fatores, associados, motivaram preocupações como as levantadas 
por Giatti; Rocha (2001) e os estudos de Sgarbi (2003a) e Scaleante (2003). A menção literal de volumes diários de visitação compreendidos à época como "alarmantes" é posicionada no contexto das propostas de capacidade de carga para a caverna Santana na Figura 3.

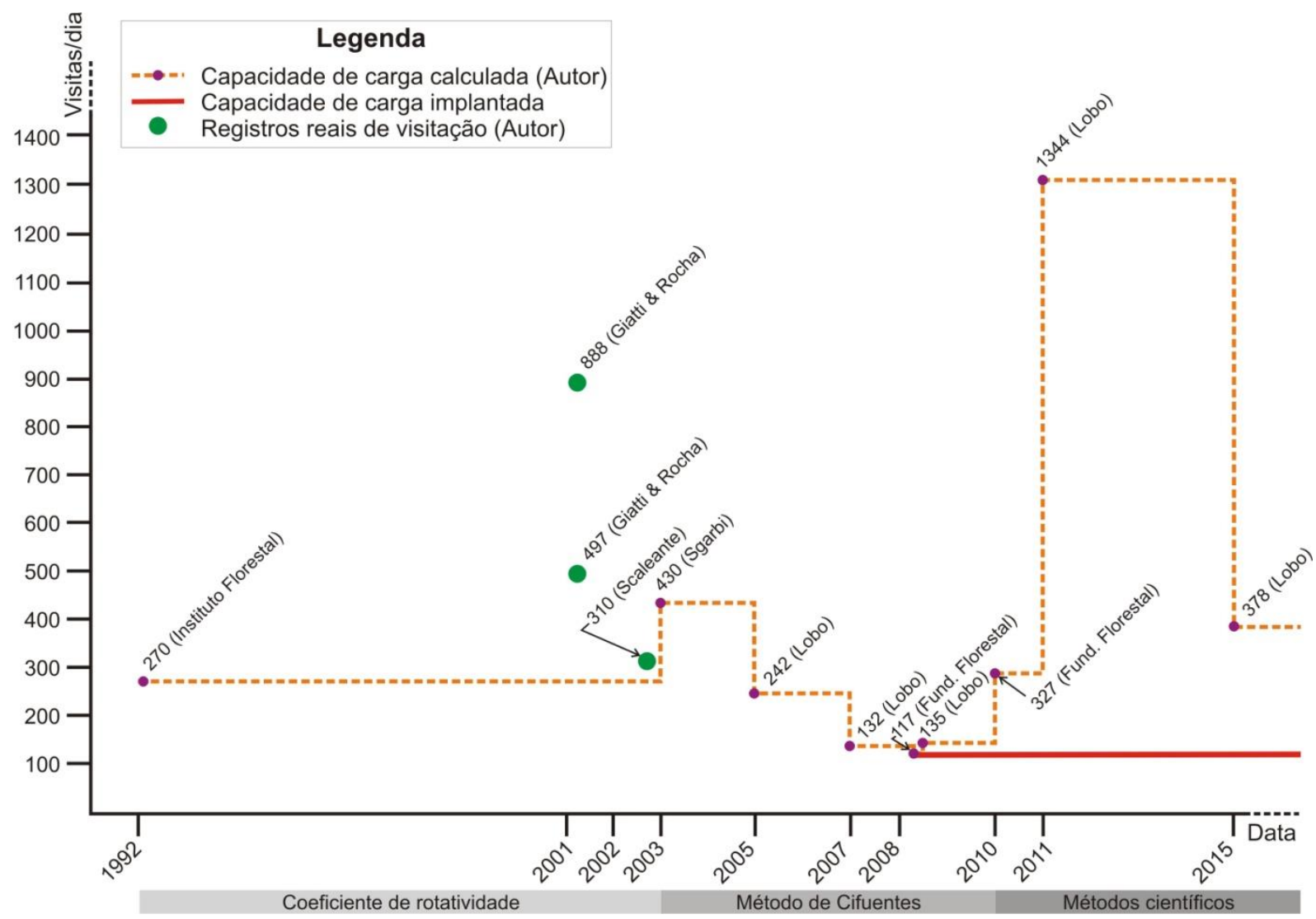

Figura 3: Registros pontuais de visitação, limites propostos e capacidade de carga atual da caverna Santana.

Figure 3: Visitation records, proposed limits and current carrying capacity of Santana cave.

A análise dos trabalhos publicados (GIATTI; ROCHA, 2001; PIVA, 2003; SCALEANTE, 2003, entre outros) que mencionam a questão da capacidade de carga da caverna Santana desvela um aspecto em comum: a defesa da aplicação da técnica como parte da solução para os problemas de ausência de ordenação e gestão da visitação. Embora as teorias de capacidade de carga remetam à esta possibilidade, como citam Cifuentes (1992) e Mexa; Coccossis (2004), deve-se ponderar que, por essência, a ordenação da visitação é a premissa e a capacidade de carga pode ser um dos meios - não o contrário.

Nesse contexto, Giatti; Rocha (2001) apontaram para a necessidade de ações em função dos picos de visitação registrados no feriado nacional do Carnaval de 2001 (Figura 3) e Scaleante (2003) reforçou a questão com base em testes realizados em julho de 2002 (Figura 3). Este último contrasta a diferença entre os impactos gerados no ambiente por grupos menores usando carbureteiras em comparação com grupos maiores sem uso de 
carbureteiras. Trata-se de uma das primeiras menções mais específicas a uma prática de visitação como fator interveniente na questão dos limites de uso e suas consequências. Esta diretriz de gestão somente voltou a ser aplicada na prática nos trabalhos de capacidade de carga na Santana a partir de 2010, com a elaboração de seu PME. Atribui-se este fato à própria evolução nos métodos de obtenção de capacidade de carga, que em versões mais recentes, começaram a considerar os distintos perfis de visitantes e mesmo a sazonalidade da visitação. Estes fatores foram aplicados de forma incisiva nos trabalhos de Fundação Florestal (2010) e Lobo $(2011,2015)$.

Outro aspecto analisado é a mudança ocorrida nos métodos utilizados para obter os limites diários de visitação. Em um primeiro momento (anos de 1990), observou-se o uso dos denominados "coeficientes de rotatividade", conforme classificação de Lobo et al. (2010). Estes consideram a relação espaço versus tempo, bem como os padrões de visitação que são determinados (de forma arbitrária ou participativa). Trata-se de uma perspectiva simplificada de controle, que pode ser utilizada como primeiro passo para o processo de obtenção de limites de visitação. Posteriormente, os estudos desenvolvidos entre 2003 e 2008 utilizaram o método de Cifuentes (CIFUENTES, 1992; CIFUENTES-ARIAS et al., 1999). A lógica de obtenção dos limites diários neste método, embora largamente utilizada, foi adequadamente criticada nos trabalhos de Delgado (2007) e de Lobo et al. (2010). Entre os aspectos levantados nestes estudos e que demonstram as fraquezas do método de Cifuentes, é feito o destaque para a sobreposição de fatores que limitam a visitação. Com isso, prejudica-se a análise de nexo causal entre a visitação e seus possíveis impactos.

A última fase dos estudos de capacidade de carga da caverna Santana tem como marco as pesquisas do PME, em 2010. Deste em diante, observou-se o uso de métodos científicos, com as seguintes características: a) processos participativos e resultados provisórios, sujeitos à revisão por monitoramento (FUNDAÇÃO FLORESTAL, 2010); b) processos participativos e cálculos determinísticos, que definem os resultados com base nos impactos registrados durante testes-piloto (LOBO, 2011); e c) processos participativos e verificação dos limites de visitação propostos por stakeholders envolvidos, por meio de estudos de impactos e algoritmos que relacionam os resultados com a capacidade de retorno do ambiente ao seu estado estacionário prévio ao impacto (LOBO, 2015).

Além disso, a Figura 3 também ilustra a situação ainda vigente (abr./2017, fechamento deste artigo) da capacidade de carga da caverna Santana: máximo de 117 visitas diárias, incluindo monitores ambientais. Este número é o mais baixo de todos os resultados obtidos pelos diversos estudos elaborados para a caverna e vigora em função de um TAC e seu respectivo Plano Emergencial de Uso Público, elaborado em 2008. Desde então, o PME da caverna já foi elaborado e aprovado, inclusive com um limite provisório novo que determina o total de 288 visitas diárias (Tabela 1), para o circuito tradicional de visitação em finais de semana e feriados. Borsanelli; Lobo (2015) apontam diversos problemas em função dos limites não terem ainda sido revistos, sobretudo nos feriados prolongados, quando 
o fluxo de visitação no PETAR é mais pronunciado. Os autores mencionam as longas filas de espera para visitar a caverna, a incerteza sobre a possibilidade de visitação - gerada pelo limite demasiadamente restritivo em conjunto com a impossibilidade de se realizar o agendamento prévio do horário de visita - e a manifestada insatisfação dos visitantes e alguns stakeholders envolvidos com o uso público no PETAR.

Neste aspecto se observa um paradoxo em relação ao uso público dito sustentável de um atrativo inserido em uma área natural protegida. $\mathrm{Na}$ maioria dos casos semelhantes no Brasil, destaca-se o notório problema de falta de estudos sobre a capacidade de carga, gerando incerteza e insegurança para seu uso público. No entanto, na caverna Santana, o mesmo cenário de incerteza e insegurança se faz presente, a despeito da profusão de estudos sobre a capacidade de carga. Esta situação reforça a posição de que a capacidade de carga é somente um componente do processo de gestão - podendo, assim, ser parte da solução ou mesmo do problema.

\section{Conclusões}

Em atividades de turismo que buscam ser caracterizadas como ecoturismo ou turismo sustentável, é evidente e legítima a preocupação com os limites de uso dos recursos naturais. Especificamente no ecoturismo, não se trata somente da adoção de uma visão equilibrada de planejamento, com princípios de sustentabilidade e processos participativos: os recursos naturais são pré-requisitos para sua existência.

Se a conservação aliada ao uso é ponto pacífico, o uso da capacidade de carga como método operacional de parte deste processo não é absolutamente consensual. Em parte, as críticas existentes se devem ao predomínio da visão quantitativa e determinística de alguns métodos amplamente difundidos. Nestes, os limites de visitação são estabelecidos por profissionais especialistas, com base em algoritmos de cálculo que padecem da falta de lógica processual, preterida em função da exatidão numérica. No caso da caverna Santana, o uso de métodos com tais características teve seu auge entre 2005 e 2008. As diversas aplicações do método de Cifuentes tiveram resultados distintos entre si, variando entre 117 e 430 visitas diárias, em função das variáveis usadas nos diferentes cálculos executados.

Uma nova fase na obtenção de limites diários de visitação na caverna Santana se inaugurou com a publicação de seu PME em 2010. O uso de procedimentos científicos e a ampliação da base participativa na obtenção da capacidade de carga conferiram novos contornos para os métodos utilizados e seus resultados. As variações nos resultados, no entanto, continuaram bastante dilatadas: entre 327 (sendo 288 o número de visitas para o roteiro tradicional da caverna, o mesmo que é focado nos demais trabalhos) e 1344 visitas diárias. Observando-se tamanha variação, retomase a questão que motivou a elaboração deste artigo: qual a capacidade de carga turística da caverna Santana? 
O que se pode afirmar com certeza é que o total de 117 visitas diárias, bem como os demais resultados obtidos pelo método de Cifuentes, não correspondem à realidade da caverna. Com isso, restariam os resultados obtidos nos estudos pós-2010: 288 (circuito tradicional), 378 ou 1344 visitas diárias?

O maior destes números, de 1344 visitas diárias obtido por Lobo (2011) em uma tese de doutorado, tanto foi relativizado pelo próprio autor em sua publicação posterior (LOBO, 2015) quanto apresenta padrões de visitação que seriam arriscados para a própria qualidade do roteiro proposto. Este, portanto, pode ser eliminado do conjunto de opções aceitáveis para aplicação da capacidade de carga. A dúvida se mantém em relação aos resultados de 288 ou 378 visitas diárias. Destes, o valor de 288 visitas diárias foi obtido em um método provisório, que recomenda a aplicação de monitoramentos posteriores para sua consolidação. Por sua vez, o valor de 378 visitas diárias foi obtido com base nas demandas dos stakeholders locais, tendo sido posteriormente testado e aprovado em monitoramentos espeleoclimáticos. Seria este, portanto, o resultado correto da capacidade de carga do circuito turístico tradicional da caverna Santana?

A resposta final ainda não foi obtida. Outros trabalhos de monitoramento das respostas do ambiente precisam ser testados, sobretudo da fauna e dos próprios visitantes, para a validação deste resultado ou obtenção de outro mais bem ajustado à realidade da caverna. No entanto, qualquer que seja o caso, para que o teste possa ser feito é preciso implantar, ainda que provisoriamente, um novo limite de visitas diárias. Esta ação não beneficiaria apenas o desenvolvimento científico aplicado à gestão de atrativos naturais, mas também àqueles que dependem do turismo na região do PETAR para sua sobrevivência. Um limite maior de visitas diárias implicaria em diminuição da recusa de visitantes em períodos de pico, amenizando os problemas atuais. Entende-se que este é o próximo passo, na busca por uma nova resposta sobre a capacidade de carga turística da caverna Santana.

\section{Agradecimentos}

Aos revisores da Revista Brasileira de Ecoturismo pelas contribuições realizadas ao manuscrito original.

\section{Referências}

ALLEGRINI, C.Q.S. Gestão do programa de uso público no Parque Estadual Turístico do Alto Ribeira - PETAR - Um estudo de caso de implantação de sistema de cobrança de ingressos e serviços. Dissertação (Mestrado em Ciências Ambientais) - Universidade de São Paulo, São Paulo. 1999.

BARTHOLO Jr., R.S.; CAMPOS, A.; BURSZTYN, I.; EGREJAS, M.; LIMA, R.P. Marco referencial teórico para o turismo de base comunitária. Rio de Janeiro: UFRJ, 2011. 
BASTIAN, F.; ALABOUVETTE, C. Lights and shadows on the conservation of a rock art cave: the case of Lascaux cave. International Journal of Speleology, v.38, n.1, p.55-60, 2009.

BOGGIANI, P.C.; GALATI, E.A.B.; DAMASCENO, G.A.; NUNES, V.L.B.; SHIRAKAWA, M.A.; SILVA, O.J.; MORACCHIOLI, N.; GESICKI, A.L.D., RIBAS, M.M.E.; MARRA, R.J.C.; SOUSA, B.P.C. de. Environmental diagnostics as a toll for the planning of tourist activity - the case of Lago Azul and Nossa Sra. Aparecida caves - Bonito/MS - Brazil. In: INTERNATIONAL CONGRESS OF SPELEOLOGY, 13, Brasília. Proceedings. Brasília: UIS/SBE, 2001. p. 299-300.

BOGGIANI, P.C.; SILVA, O.J.; GESICKI, A.L.D.; GALATI, E.; SALLES, L.O.; LIMA, M.M.E.R. Definição de capacidade de carga turística das cavernas do Monumento Natural Gruta do Lago Azul (Bonito, MS). Geociências, Rio Claro, v.26, n.4, p.333-348, 2007.

BORSANELLI, F.A.; LOBO, H.A.S. Impactos causados à comunidade local com o fechamento das cavernas turísticas do PETAR em 2008 na visão dos stakeholders envolvidos. In: RASTEIRO, M.A.; SALLUN FILHO, W. Anais do $33^{\circ}$ Congresso Brasileiro de Espeleologia. Campinas: SBE, 2015. p.719-727.

BRANDI, R. Ricardo Krone e Lourenço Granato: influências na história da espeleologia paulista no final do século XIX e início do século XX. O Carste, v.20, n.1, p.36-61, 2008.

CALAFORRA, J.M.; FERNÁNDEZ-CORTÉS, A.; SÁNCHEZ-MARTOS, F.; GISBERT, J.; PULIDO-BOSCH, A. Environmental control for determining human impact and permanent visitor capacity in a potential show cave before tourist use. Environmental Conservation, v.30, n.2, p.160-167, 2003.

CEBALLOS-LASCURAIN, $H$. Ecoturismo, naturaleza y desarrollo sostenible. Cidade do México: Diana, 1998. 172 p.

CIFUENTES, M. Determinación de capacidad de carga turística en áreas protegidas. Turrialba: CATIE, 1992. $28 \mathrm{p}$.

CIFUENTES-ARIAS, M.; MESQUITA, C.A.B.; MÉNDEZ, J.; MORALES, M.E.; AGUILAR, N.; CANCINO, D.; GALLO, M.; RAMIREZ, C.; RIBEIRO, N.; SANDOVAL, E.; TURCIOS, M. Capacidad de carga turística de las áreas de uso público del Monumento Nacional Guayabo, Costa Rica. Turrialba: CATIE/WWF, 1999. 99 p.

CIGNA, A.A. Environmental management of tourist caves: the examples of Grotta di Castellana and Grotta Grande del Vento, Italy. Environmental Geology, Berlin, v.21, p.173-180, 1993.

CIGNA, A.A.; BURRI, E. Development, management and economy of show caves. International Journal of Speleology, v.29, n.1, p.1-27, 2000.

CONAMA - CONSELHO NACIONAL DO MEIO AMBIENTE. Resolução CONAMA n' 347 de 10 de setembro de 2004. In: Diário Oficial da União, Brasília, ed.176, seção 01, p.54. 13 set. 2004.

CRUZ JÚNIOR, F.W. da.; BURNS, S.J.; KARMANN, I.; SHARP, W.D.; VUILLE, M.; CARDOSO, A.O.; FERRARI, J.A.; DIAS, P.L.S.; VIANA JÚNIOR, O. Insolation-driven changes in atmosferic circulation over the past 116,000 years in subtropical Brazil. Nature, v.434, n.3, p.63-66, 2005. 
DELGADO, M. Análise da metodologia criada por Miguel Cifuentes referente à capacidade de carga turística. Turismo em Análise, São Paulo, v.18, n.1, p.73-93, 2007.

DIEGUES, A.C.S. O mito moderno da natureza intocada. 3.ed. São Paulo: Hucitec, 2000. 169 p.

FENNELL, D.A. Ecotourism. London: Routledge, 2014.

FERNÁNDEZ-CORTÉS, A.; CALAFORRA, J.M.; SÁNCHEZ-MARTOS, F.; GISBERT, J. Microclimate processes characterization of the giant geode of Pulpí (Almería, Spain): technical criteria for conservation. International Journal of Climatology, v.26, p.691-706, 2006.

FIGUEIREDO, L.A.V. de. Cavernas brasileiras e seu potencial ecoturístico: um panorama entre a escuridão e as luzes. In: VASCONCELOS, F.P. (org.) Turismo e meio ambiente. Fortaleza: UECE, 1998. p.186-200.

FIGUEIREDO, L.A.V. de. "O 'meio ambiente' prejudicou a gente...": políticas públicas e representações sociais de preservação e desenvolvimento; desvelando a pedagogia de um conflito no Vale do Ribeira (Iporanga-SP). 489 p. Dissertação (Mestrado em Educação), Faculdade de Educação, Universidade Estadual de Campinas, Campinas. 2000.

FIGUEIREDO, L.A.V. de. Cavernas como paisagens racionais e simbólicas: imaginário coletivo, narrativas visuais e representações da paisagem e das práticas espeleológicas. 466 p. Tese (Doutorado em Geografia Física) Faculdade de Filosofia, Letras e Ciências Humanas, Universidade de São Paulo, São Paulo. 2010.

FOGAÇA, I.F. Estudo das transformações da estrutura física do bairro da Serra, entorno do PETAR, em decorrência da atividade turística. Pesquisas em Turismo e Paisagens Cársticas, v.1, n.1, p.29-42, 2008.

FUNDAÇÃO FLORESTAL/SECRETARIA DO MEIO AMBIENTE. Laudo de capacidade de carga real (CCR) da caverna de Santana (PETAR, SP). São Paulo: Fundação Florestal, 2008.

FUNDAÇÃO FLORESTAL/SECRETARIA DO MEIO AMBIENTE. Plano de manejo espeleológico do Parque Estadual Turístico do Alto Ribeira. São Paulo: Fundação Florestal, 2010. 765 p.

GIATTI, L.L.; ROCHA, A.A. Impactos Ambientais do Turismo na Região do PETAR - Parque Estadual Turístico do Alto Ribeira - São Paulo - Brasil. In: Proceedings of 13th. International Congress of Speleology. Brasília: UIS/SBE, 2001. p.711-715.

GILLIESON, D. Caves: processes, development and management. Cambridge: Blackwell, 1996. 324 p.

HEATON, T. Caves: a tremendous range in energy environments on earth. National Speleological Society News, v.08, n.44, p.301-304, 1986.

HOYOS, M.; SOLER, V.; CAÑAVERAS, J.C.; SÁNCHEZ-MORAL, S.; SANZRUBIO, E. Microclimatic characterization of a karstic cave: human impact on microenvironmental parameters of a prehistoric rock art cave (Candamo cave, Northern Spain). Environmental Geology, Berlin, v.33, n.4, p.231242, 1998. 
INSTITUTO FLORESTAL. Portaria IF-1 de 19 de maio de 1992. São Paulo: Instituto Florestal, 1992.

KARMANN, I. Evolução e dinâmica atual do sistema cárstico do Alto Vale do Rio Ribeira de Iguape, Sudeste do estado de São Paulo. 228 p. Tese (Doutorado em Geoquímica) - Instituto de Geociências, Universidade de São Paulo, São Paulo. 1994.

KNECHT, T. Formações estruturaes, particularmente karsticas do município de Apiaí (Estado de S. Paulo). Geografia, São Paulo, v.1, n.1, p.98-109, 1935.

LE BRET, M. Maravilhoso Brasil subterrâneo. Jundiaí: Japi/SBE, 1995. $204 \mathrm{p}$.

LINO, C.F. Vale do Ribeira: alternativa turismo. 1976. Monografia (Graduação em Arquitetura e Urbanismo), Faculdade de Arquitetura e Urbanismo, Universidade Mackenzie. São Paulo.

LOBO, H.A.S. Considerações preliminares para a reestruturação turística da caverna de Santana - PETAR, Iporanga, SP. In: CONGRESSO BRASILEIRO DE ESPELEOLOGIA, 28, Campinas. Anais. Campinas: SBE, 2005. p. 77-87.

LOBO, H.A.S. Os níveis de circulação de energia como fator de correção na capacidade de carga turística. In: Resumos Expandidos e Simples do II Encontro Brasileiro de Estudos do Carste. São Paulo: Redespeleo, 2007. p.107-112.

LOBO, H.A.S. Capacidade de carga real (CCR) da caverna de Santana, PETAR-SP e indicações para o seu manejo turístico. Geociências, Rio Claro, v.27, n.3, p.369-385, 2008.

LOBO, H.A.S. Estudo da dinâmica atmoférica subterrânea na determinação da capacidade de carga turística na caverna de Santana (PETAR, IporangaSP). Tese (Doutorado em Geociências e Meio Ambiente) - Universidade Estadual Paulista Júlio de Mesquita Filho, Rio Claro. 2011.

LOBO, H.A.S. Tourist carrying capacity of Santana cave (PETAR-SP, Brazil): A new method based on a critical atmospheric parameter. Tourism Management Perspectives, v.16, p.67-75, 2015.

LOBO, H.A.S.; ZAGO, S. Classificação dos níveis de circulação de energia no circuito turístico da Caverna de Santana - PETAR - Iporanga, SP. In: ENCONTRO BRASILEIRO DE ESTUDOS DO CARSTE, 2, São Paulo, Brasil. Resumos expandidos e simples. São Paulo: Redespeleo, 2007. p.113-122.

LOBO, H.A.S.; BOGGIANI, P.C. ; PERINOTTO, J.A.J. Tourist carrying capacity in caves: main trends and new methods in Brazil. In: Proceedings of 6th Congress of International Show Caves Association. Liptovsky Mikulas: State Nature Conservance of the Slovak Repubic, 2010.

LOBO, H.A.S.; TRAJANO, E.; MARINHO, M. A.; BICHUETTE, M. E.; SCALEANTE, J. A.; SCALEANTE, O. A.; LATERZA, F. V. Projection of tourist scenarios onto fragility maps: Framework for determination of provisional tourist carrying capacity in a Brazilian show cave. Tourism Management, v.35, p.234-243, 2013.

667 Revista Brasileira de Ecoturismo, São Paulo, v.10, n.3, ago-out 2017, pp. 645-669. 
LOBO, H.A.S.; BOGGIANI, P.C.; SAYEG, I.J.; PERINOTTO, J.A.J. Impactos ambientais em espeleotemas causados pela visitação pública com carbureteiras na caverna Santana (Parque Estadual Turístico do Alto Ribeira, Iporanga-SP). Geociências, v.34, p.103-115, 2015.

MANGIN, A.; BOURGES, F.; D'HULST, D. La conservation des grottes ornées: um problème de stabilité d'un système naturel (l'e exemple de la grotte préhistorique de Gargas, Pyrénées françaises). Sciences de la Terre et des Planètes, v.328, n.5, p.295-301, 1999.

MANNING, R.E. How much is too much? Carrying capacity of National Parks and protected areas. In: ARNBERGER, A.; BRANDENBURG, C.; MUHAR, A. (eds.) Proceedings International Conference on Monitoring and Management of Visitor Flows in Recreational and Protected Areas. Viena: Bodenkultur University, 2002. P.306-313.

MARINHO, M.A. Contribuição à geomorfologia cárstica do Vale do Betari, Iporanga - Apiaí, São Paulo. 73 p. Trabalho de Conclusão de Curso (Graduação em Geografia) - Faculdade de Filosofia, Letras e Ciências Humanas, Universidade de São Paulo, São Paulo. 1992.

MARINHO, M.A. (Coord.) Projeto "plano de uso recreativo do PETAR, Iporanga e Apiaí/SP. São Paulo: WWF/lng_Ong, 2002. 94p.

MARRA, R.J.C. Espeleo turismo: planejamento e manejo de cavernas. Brasília: WD Ambiental, 2001. 224 p.

MCCOOL, S.F.; LIME, D.W. Tourism carrying capacity: tempting fantasy or useful reality? Journal of Sustainable Tourism, v.9, p.372-388, 2001.

MEXA, A.; COCCOSSIS, H. Tourism carrying capacity: a theoretical overview. In: COCCOSSIS, H.; MEXA, A. The challenge of tourist carrying capacity assessment. Surrey: Ashgate, 2004. p.37-55.

MINISTÉRIO DO TURISMO. Ecoturismo: orientações básicas. Brasília: MinTur, 2010. 90 p.

NEIMAN, Z. A educação ambiental através do contato dirigido com a natureza. 138 p. Tese (Doutorado em Psicologia) - Universidade de São Paulo, São Paulo. 2007.

PIVA, E.B. Avaliação e tipificação dos impactos do uso público nos núcleos Santana e Ouro Grosso - Parque Estadual Turístico do Alto Ribeira PETAR (Apiaí - SP). Monografia (Bacharelado em Ciências Biológicas) Universidade Federal de São Carlos, São Carlos. 2003.

SCALEANTE, J.A.B. Avaliação do impacto de atividades turísticas em cavernas. 82 p. Dissertação (Mestrado em Geociências) - Instituto de Geociências, Universidade Estadual de Campinas, Campinas. 2003.

SGARBI, M.C. Metodologia de manejo em cavernas para minimização de impactos ambientais decorrentes de atividade antrópica - Estudo de caso gruta do Chapéu e caverna Santana, Parque Estadual do Alto Ribeira/SP. 47 p. Relatório de Iniciação Científica (Graduação em Ciências Biológicas) Universidade de Mogi das Cruzes, Mogi das Cruzes. 2003a. 
SGARBI, M.C. Manejo em cavernas para minimização de impactos ambientais decorrentes de atividade antrópica: estudo de caso da caverna Santana, Parque Estadual do Alto Ribeira/SP. Mogi das Cruzes: Universidade de Mogi das Cruzes, 2003b.

SBE - SOCIEDADE BRASILEIRA DE ESPELEOLOGIA. Cadastro nacional de cavernas do Brasil (CNC). Campinas: SBE, 2017. Disponível em: <http://www.cavernas.org.br>. Acesso em: 14 abr. 2017.

SWARBROOKE, J. Turismo sustentável: conceitos e impactos ambientais. São Paulo: ALEPH, 2000.

TRAJANO, E. Políticas de conservação e critérios ambientais: princípios, conceitos e protocolos. Estudos Avançados, São Paulo, v.24, n.68, p.135146, 2010.

VIANA JÚNIOR, O. Hidroquímica, hidrologia e geoquímica isotópica $(\mathrm{O}$ e $\mathrm{H})$ da fácies de percolação vadosa autogênica, caverna Santana, Município de Iporanga, Estado de São Paulo. 113 p. Dissertação (Mestrado em Geoquímica) - Instituto de Geociências, Universidade de São Paulo, São Paulo. 2002.

WAGAR, J.A. The carrying capacity of wild lands for recreation. Washington: Society of American Foresters, 1964.

WAGAR, J.A. Recreational Carrying Capacity Reconsidered. Journal of Forestry, v.72, p.274-278, 1974.

ZAKAIA, D; CHADWICK-FURMAN, N.E. Impacts of intensive recreational diving on reef corals at Eilat, northern Red Sea. Biological Conservation, v.105, p.179-187, 2002.

ZAOUAL, $\mathrm{H}$. Do turismo de massa ao turismo situado: quais as transições? Caderno Virtual de Turismo, v.8, n.2, p.1-14, 2008.

ZELENKA, J.; KACETL, J. The concept of carrying capacity in tourism. Amfiteatru Economic, v.16, p.641-654, 2014.

Heros Augusto Santos Lobo: Universidade Federal de São Carlos, Sorocaba, SP, Brasil.

E-mail: heroslobo@ufscar.br

Link para o currículo Lattes: http://lattes.cnpq.br/9405961078398915

Data de submissão: 18 de Abril de 2017

Data de recebimento de correções: 27 de maio de 2017

Data do aceite: 27 de maio de 2017

Avaliado anonimamente 